\title{
Rhizobacteria-Mediated Growth Promotion of Tomato Leads to Protection Against Cucumber mosaic virus
}

\author{
John F. Murphy, M. S. Reddy, Choong-Min Ryu, Joseph W. Kloepper, and Ruhui Li
}

Department of Entomology \& Plant Pathology, 209 Rouse Life Sciences Building, Auburn University, AL 36849.

Accepted for publication 2 May 2003.

\section{ABSTRACT}

Murphy, J. F., Reddy, M. S., Ryu, C.-M., Kloepper, J. W., and Li, R. 2003. Rhizobacteria-mediated growth promotion of tomato leads to protection against Cucumber mosaic virus. Phytopathology 93:13011307.

We evaluated combinations of two strains of plant growth-promoting rhizobacteria (PGPR) formulated with the carrier chitosan for the ability to induce growth promotion of tomato plants and resistance to infection by Cucumber mosaic virus (CMV). Each PGPR combination included GB03 (Bacillus subtilis) and one of the following PGPR strains: SE34 (B. pumilus), IN937a (B. amyloliquefaciens), IN937b (B. subtilis), INR7 (B. pumilus), or T4 (B. pumilus). The PGPR combinations formulated with chitosan are referred to as biopreparations. Tomato plants treated with each of the biopreparations appeared phenotypically and developmentally similar to nonbacterized control plants that were 10 days older (referred to as the older control). When plants were challenged with CMV, all plants in the biopreparation treatments and the older control treatment had significantly greater height, fresh weight, and flower and fruit numbers than that of plants in the CMV-inoculated same age control treatment. CMV disease severity ratings were significantly lower for biopreparation-treated and older control tomato plants than for that of same age control plants at 14 and 28 days postinoculation (dpi). CMV accumulation in young noninoculated leaves was significantly less for all biopreparation-treated plants and those in the older control than for the same age control plants at $14 \mathrm{dpi}$ and for four of the five biopreparation treatments at $28 \mathrm{dpi}$. In those tomato plants shown to be infected, the amount of CMV in noninoculated leaves was significantly lower for three of the biopreparation treatments and the older control treatment at 14 dpi and biopreparation G/INR7 treatment at 28 dpi when compared with the control treatment. These data show that treatment of tomato plants with biopreparations results in significant enhancement of growth and protection against infection by CMV.
Since 1994, we have investigated the use of plant growth-promoting rhizobacteria (PGPR) to induce resistance to infection by Cucumber mosaic virus (CMV, genus Cucumovirus).

CMV was chosen because of its importance as a pathogen to many agricultural crops worldwide (20) and because of severe losses sustained each year in fresh-market tomato in Alabama (29). Initial studies were carried out in the greenhouse and involved the application of single strains of PGPR to cucumber and tomato as seed treatments (24). When CMV was mechanically inoculated onto the cotyledons of cucumber seedlings, there was a 1-week delay in the onset of symptoms in some PGPR-treated plants compared with nonbacterized CMV-inoculated controls. The PGPR-treated plants that did not develop symptoms by 7 days postinoculation (dpi) remained symptomless throughout the experiment (study ended at $28 \mathrm{dpi}$ ) and contained no detectable amounts of CMV in noninoculated leaves. The PGPR treatments used in the cucumber experiments, when applied to tomato seed, significantly reduced the area under the disease progress curve of CMV-inoculated plants compared with nonbacterized CMVinoculated controls. The induced resistance elicited by PGPR in tomato to CMV was further evaluated with additional PGPR strains in greenhouse and field experiments (36). Protection was observed when experiments were conducted in the greenhouse and for plants inoculated with CMV in the greenhouse and then transplanted to the field. These findings illustrate that the induced resistance observed in the greenhouse was sustained under field conditions when plants were artificially inoculated with CMV.

Corresponding author: J. F. Murphy; E-mail address: jmurphy@acesag.auburn.edu

Publication no. P-2003-0818-02R

(C) 2003 The American Phytopathological Society
PGPR-mediated induced resistance also was reported against Tobacco necrosis virus (TNV) (17) and Tobacco mosaic virus (TMV) (7) in tobacco. In each case, a single PGPR strain was used as the inducing agent, and the virus infection resulted in a local lesion response so resistance was evaluated as a reduction in lesion number and size. The resistance induced by Pseudomonas fluorescens strain $\mathrm{CHAO}$ against TNV resulted in reduced lesion numbers and size (17), whereas $P$. aeruginosa strain 7NSK reduced the size of lesions caused by TMV infection (7). In contrast to the protective effects of the PGPR treatments described previously, Ton et al. $(33,34)$ did not observe PGPR-mediated induced resistance to systemic infection by Turnip crinkle virus in Arabidopsis spp.

The use of single PGPR strains as inducing agents provided protection against viral pathogens; however, variability in efficacy of some PGPR strains due to different soil and environmental conditions led to studies that evaluated mixtures of PGPR strains (23). Following this approach, selected PGPR strains shown to induce resistance in previous experiments were evaluated as paired combinations for elicitation of induced resistance to the whiteflytransmitted Tomato mottle virus (ToMoV; genus Begomovirus) under field conditions consisting of heavy whitefly and ToMoV pressure (18). Some PGPR treatments had significantly lower disease severity ratings, a lower percentage of infected plants based on detection of ToMoV DNA in foliar tissues, and larger yields compared with a nonbacterized control treatment. This protection was observed at 40 days after transplant but was not observed by 80 days after transplant. Furthermore, there was a gradual decline in protection over the course of three trials. Although the cause of this decline was not determined, the occurrence of other viruses identified in tomato samples may have been a factor in the reduced protection by the PGPR treatments.

Although the described studies focus on the use of PGPR to induce resistance against viruses and other pathogens, recent efforts 
have shifted to evaluate the enhanced plant growth effects that result from treatments consisting of combinations of selected PGPR strains formulated in the carrier chitosan (12). The actual function of chitosan in these formulations has not been delineated; however, chitosan treatments alone have resulted in low levels of disease resistance (4) and enhancement of soil microflora (25). The combination of PGPR strains and chitosan increases the likelihood of induced resistance and enhanced plant growth under varying growth conditions (12). We hypothesize that enhanced plant growth would shorten the time required for expression of mature plant resistance. Plants vary in their susceptibility to infection by certain pathogens due to their age or stage of development, a process referred to as age-related or mature plant resistance $(9,14,22,30)$. Age-related resistance, whereby a crop is planted early or late in the season in an effort to avoid availability of young, highly susceptible plants at a time when insect vector densities achieve a specified threshold, has been used as a strategy to reduce losses caused by plant viruses $(15,35)$. This approach has been successful with some plant $\times$ virus combinations, often leading to increases in yield relative to plants that became infected at early stages of development $(1,2,5,8,13,15,16,21,26-29,31,32)$.

In our previous work, PGPR were applied as single strains (24, $36)$ or combinations of two strains (18) that led to induced resistance against virus infection with no enhancement in plant growth. We show in this report that treatment of tomato seed with combinations of selected PGPR strains formulated in chitosan results in enhanced plant growth leading to tomato plants that are phenotypically similar to plants that are 10 days older and are protected from $\mathrm{CMV}$ infection in a manner that mimics mature plant resistance.

\section{MATERIALS AND METHODS}

Plant growth conditions and PGPR treatments. Six PGPR preparations (each shown in previous studies to induce resistance) consisting of industrially formulated endospores were used in each experiment. Each PGPR treatment consisted of preparations of two Bacillus strains (Table 1) and chitosan as the formulation carrier. Each preparation contained a final concentration of $1 \times$ $10^{7} \mathrm{CFU}$ per $\mathrm{cm}^{3}$ of potting medium of each bacterium. The formulation of two PGPR strains and chitosan is referred to as a biopreparation. The five different biopreparations listed in Table 1 were supplied by Gustafson, Inc. (Plano, TX). Each biopreparation was mixed into soilless growth medium (Speedling Inc., Bushnell, FL) at a ratio of 1:40 (vol/vol). Tomato cv. Solar Set seed was sown directly into the amended soilless growth medium and maintained in a temperature-controlled greenhouse at the Plant Science Greenhouse Complex at Auburn University, Alabama. Ambient air temperatures in the greenhouse were maintained at $28^{\circ} \mathrm{C}$ day $/ 21^{\circ} \mathrm{C}$ night throughout the year. Watering procedures were carried out routinely by greenhouse personnel with no fertilization applied. A single Styrofoam seeding tray, containing 128 wells per tray, was used for each treatment (i.e., biopreparation and controls) in order to avoid contamination between treatments.

TABLE 1. List of plant growth-promoting rhizobacteria (PGPR) strains used in the biopreparation formulations

\begin{tabular}{lll}
\hline Biopreparation treatment ${ }^{\mathrm{y}}$ & \multicolumn{2}{c}{ PGPR strains $^{\mathrm{z}}$} \\
\hline G/SE34 & GB03 + SE34 & (Bacillus pumilus) $_{\text {G/IN937a }}$ \\
G/IN937b & GB03 + IN937a & (B. amyloliquefaciens) \\
G/INR7 & GB03 + IN937b & (B. subtilis) \\
G/T4 & GB03 + INR7 & (B. pumilus) \\
\hline
\end{tabular}

${ }^{y}$ Each biopreparation consisted of endospore preparations of two PGPR strains formulated with the carrier chitosan. Each treatment contained a final concentration of $1 \times 10^{7} \mathrm{CFU}$ per $\mathrm{cm}^{3}$ of potting medium of each bacterium.

${ }^{z}$ The bacterial name indicated in parentheses refers to the second component of each PGPR combination. GB03 $=$ B. subtilis.
Treatments consisted of five biopreparations and two nonbacterized control treatments. The first nonbacterized control treatment (referred to simply as the control treatment) included tomato plants sown on the same date as those treated with each of the biopreparations. This control treatment represented plants that were the same age as those treated with the biopreparations. The second nonbacterized control treatment consisted of tomato plants sown 10 days prior to plants in each of the other treatments. This second control treatment, referred to as the older control, provided plants that were similar in size to those treated with the biopreparations (because the biopreparations promote plant growth [12]). Previous experiments that included a control treatment consisting of chitosan without the addition of PGPR did not result in the enhanced growth obtained when the treatment included PGPR (data not shown; 12). Therefore, a chitosan only control treatment was not included.

At 3 weeks postgermination (germination among treatments occurred at approximately the same time), each seedling was transplanted to a 2-liter pot containing the soilless potting medium ProMix (Premier Peat, Riviére-du-Loup, Québec, Canada). Treatments were arranged in a randomized complete block design with five plants of each treatment per replication and four replications per treatment. Plants were maintained at the Plant Science Greenhouse Complex as described previously.

Virus inoculation. CMV subgroup I strain Fny was provided by P. A. Palukaitis (Scottish Crop Research Institute, Invergowrie, Scotland) and used throughout this study. CMV was maintained by mechanical passage in Nicotiana tabacum 'Kentucky 14' and Capsicum annuum 'Early Calwonder'. CMV inoculum consisted of systemically infected Kentucky 14 leaf tissue ground in $50 \mathrm{mM}$ potassium phosphate buffer, $\mathrm{pH} 7.0$, containing $10 \mathrm{mM}$ sodium sulfite at a ratio of $1 \mathrm{~g}$ of tissue per $10 \mathrm{ml}$ of buffer. Buffer, mortars, and pestles were chilled prior to use and maintained on ice during inoculations. Two experiments were performed, in each case, 20 tomato plants per treatment were mechanically inoculated with CMV or subjected to mock inoculation when plants in the same age control treatment were at the early five- to six-leaf stage (i.e., leaves five and six were no more than $1 \mathrm{~cm}$ in length). The first three leaves on each plant were lightly dusted with Carborundum prior to rub-inoculation with CMV.

Evaluation of plant growth characteristics and disease assessments. Plant growth characteristics for biopreparation and control treatments were evaluated for CMV- and mock-inoculated plants. Stem growth was the difference in stem height (measured from soil line to shoot apex) taken 1 day prior to inoculation with $\mathrm{CMV}$ and at $30 \mathrm{dpi}$. A second growth characteristic, fresh weight of aboveground tissue, was determined at 30 dpi. Finally, the number of flowers and fruits (taken as a single measure) were counted on each plant at $30 \mathrm{dpi}$.

Disease assessments were made throughout the experiment; however, specific disease severity ratings were made at 14 and $28 \mathrm{dpi}$. Disease severity was measured using the following rating scale: $0=$ no symptoms, $2=$ mild mosaic symptoms on leaves, $4=$ severe mosaic symptoms on leaves, $6=$ mosaic and deformation of leaves, $8=$ severe mosaic and severe deformation of leaves, and $10=$ severe mosaic and deformation of leaves with stunted growth. Each disease severity rating evaluation was performed with mockinoculated plants of the respective treatment as a standard.

CMV accumulation in foliar tissues was determined by enzymelinked immunosorbent assay (ELISA). Each plant was sampled at 14 and 28 dpi by collection of three terminal leaflets from three young, noninoculated leaves. The three leaflets were pooled into a single sample and ground in $50 \mathrm{mM}$ carbonate buffer, $\mathrm{pH} 9.6$, at a ratio of 1:25 ( $1 \mathrm{~g}$ of tissue per $25 \mathrm{ml}$ of buffer). All steps in the ELISA procedure were described previously (10). Samples were considered positive for the presence of CMV when the absorbance value (at $405 \mathrm{~nm}$ ) was greater than the mean plus 3 standard deviations for comparable healthy control samples. Each ELISA test 
included a series of known concentrations of purified CMV to standardize the ELISA reactions from one test to another (reactions were allowed to develop for approximately $30 \mathrm{~min}$ ).

Data analysis. Data were analyzed separately for each experiment by analysis of variance using JMP software (SAS Institute, Cary, NC). The significance of biopreparation treatment effects was determined by the magnitude of the $F$ value $(P=0.05)$. When a significant $F$ test was obtained for treatments, separation of means was accomplished by Fisher's protected least significant difference. The response of tomato plants treated with the different biopreparations was determined in two separate experiments. Each experiment included data for disease severity, CMV accumulation in foliar tissues based on ELISA, and percent infection. These data were pooled for statistical analyses. The second experiment included measurements on growth parameters such as height, fresh weight, and flower and fruit number.

\section{RESULTS}

Plant growth characteristics in response to PGPR and CMV. The germination and initial growth rates for plants in each treatment were similar at 1 and 2 weeks after germination. Subsequent growth for plants in each biopreparation treatment was extensively greater than for plants in the control treatment. At 5 days prior to CMV inoculation, a typical plant in the control treatment (Fig. 1A) was much smaller than a plant of the same age treated with one of the biopreparations (Fig. 1C) or a plant from the older control treatment (Fig. 1B) that was 10 days older.

Three growth parameters were evaluated at the end of the experiment (30 dpi): plant height (a measure of stem growth from 1 day prior to CMV inoculation to $30 \mathrm{dpi}$ ), plant fresh weight of aboveground tissues, and the number of flowers and fruits. An evaluation of these growth characteristics among treatments that were mock-inoculated, i.e., those not subjected to CMV inoculation (Fig. 2A to $\mathrm{C}$ ), revealed that plants treated with biopreparations G/SE34, G/INR7, and G/T4 were significantly greater in height than plants in the control treatment (Fig. 2A). Plant fresh weight of all biopreparation treatments and the older control was significantly greater than for the control treatment, with G/SE34, G/IN937a, G/IN937b, and G/INR7 being greater than both control treatments (Fig. 2B). Plants treated with biopreparation G/IN937a weighed more than those treated with G/T4. Flower and fruit numbers for all treatments of biopreparations and the older control treatment were greater than for the control (Fig. 2C). In addition, treatments with biopreparations G/IN937a and G/INR7 resulted in production of more flowers and fruits than G/SE34 and the older control.

The evaluation of plant growth parameters among treatments that were challenged with CMV also revealed differences between biopreparation treatments, the older control treatment, and the control treatment (Fig. 2D to F). The mean plant height was significantly greater for all biopreparation treatments and the older control compared with the control treatment (Fig. 2D). No significant differences were observed for plant height among biopreparation treatments and the older control treatment. The mean plant fresh weight of aboveground tissues was significantly greater for all biopreparation treatments and the older control treatment than that of the control treatment (Fig. 2E). In addition, plant fresh weights for all biopreparation treatments were significantly greater than for the older control treatment. The mean numbers of flowers and fruits, like that of plant height and weight, were significantly greater for all biopreparation treatments and the older control than for the control treatment (Fig. 2F). Biopreparation treatments G/IN937b, G/INR7, and G/T4 had significantly more flowers and fruit than plants in the G/SE34 and older control treatments.

An evaluation of the effect on plant growth characteristics for each treatment comparing those inoculated with CMV versus those subjected to mock inoculation revealed only a few differences. No differences in flower and fruit numbers occurred within any treatment. Mock-inoculated plants in biopreparation treatment G/T4 had a mean height value significantly greater than those inoculated with CMV. Plants in the control treatment that were mock-inoculated weighed significantly more than those inoculated with CMV (statistical analysis). An analysis of variance to test for a biopreparation-virus interaction revealed no interaction for plant height $\left(F_{5,165}=1.30 ; P=0.265\right)$ or fresh weight $\left(F_{5,165}=1.23 ; P=\right.$ 0.297).

CMV infection and accumulation. Initial signs of veinclearing and mosaic occurred in control treatment plants by $7 \mathrm{dpi}$, whereas plants in the other treatments were symptomless at that time. When plants were rated for symptom severity at $14 \mathrm{dpi}$, the control treatment had an average disease rating significantly higher than any of the other treatments (Fig. 3A). During that same rating period, plants treated with G/IN937a had a disease severity rating significantly lower than plants treated with G/INR7, and G/T4 and the older control treatment. In addition, tomato plants treated with biopreparation G/SE34 had a disease severity rating significantly lower than plants treated with G/T4. At 28 dpi, the disease severity rating for all biopreparation treatments and the older control treatment again were significantly lower than for plants in the control treatment (Fig. 3A). Furthermore, treatments G/SE34, G/IN937a, and G/IN937b resulted in disease severity ratings significantly lower than that of treatment G/T4.

CMV accumulation in young, noninoculated leaves was measured at 14 and 28 dpi by ELISA. At $14 \mathrm{dpi}$, the mean ELISA values for samples collected from each biopreparation treatment and the older control treatment were significantly lower than those of the control treatment (Table 2). CMV accumulation in plants treated with biopreparations G/SE34, G/IN937a, and G/IN937b and the older control were significantly lower than that of plants treated with G/T4, while significantly lower amounts of CMV accumulated in G/IN937a- and G/IN937b-treated plants than in plants treated with G/INR7. When plants were tested at $28 \mathrm{dpi}$, mean ELISA values for treatments with biopreparations G/SE34, G/IN937a, G/IN937b, and G/INR7 and the older control were significantly lower than those of G/T4 and the control treatment (Table 2).

Use of the ELISA data to determine percent infection within each treatment revealed that significantly fewer plants were infected with CMV in all biopreparation treatments (except G/T4) and the older control treatment than in the control treatment at 14 dpi (Table 2). In addition, tomato plants treated with G/SE34, G/IN937a, and G/IN937b and the older control had significantly

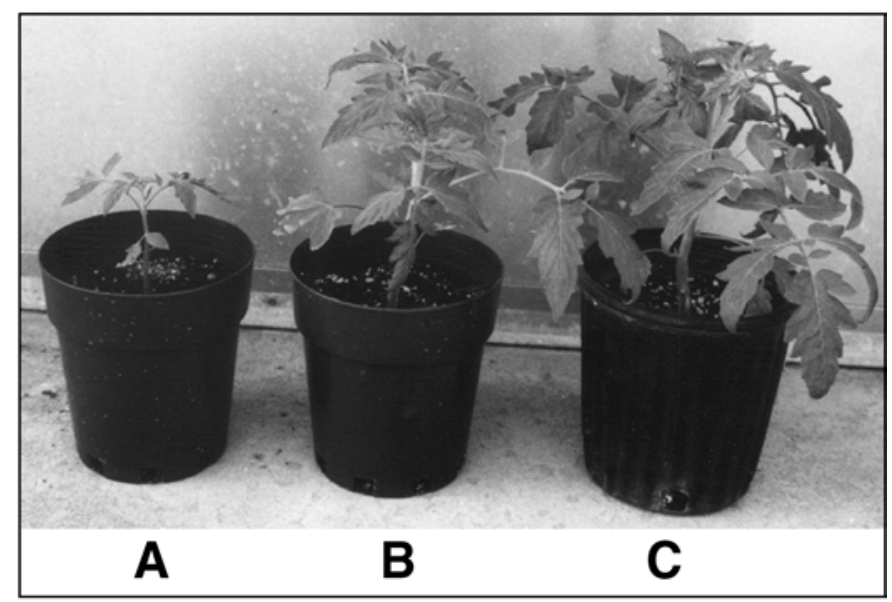

Fig. 1. Representative tomato plants for $\mathbf{A}$, control, $\mathbf{B}$, older control, and $\mathbf{C}$, biopreparation treatments. The $\mathbf{A}$, control and $\mathbf{C}$, biopreparation-treated plants are the same age, whereas $\mathbf{B}$, the older control is 10 days older. These photographs were taken 5 days prior to Cucumber mosaic virus inoculation. 
fewer plants infected than in the G/T4 treatment, and there were fewer plants infected with CMV in the G/IN937a treatment than in the G/INR7 treatment. At $28 \mathrm{dpi}$, similar to that observed at 14 dpi, significantly less CMV infection occurred in all biopreparation treatments (except G/T4) and the older control treatment than in the control treatment (Table 2). Furthermore, significantly fewer tomato plants were infected with CMV when treated with biopreparation G/SE34 than with G/IN937b and G/INR7. It should be noted that there was a reduction in the percent infection from 14 to 28 dpi for plants treated with biopreparations G/SE34 and G/INR7. Whether this resulted from reduced virus accumulation, limited movement into young tissues, or a combination of the two was not determined.
The ELISA data described previously represent the mean value for 40 plants in each treatment. When the mean ELISA absorbance value for those plants infected with CMV at 14 dpi was compared, treatments G/IN937a, G/IN937b, and G/T4 and the older control had significantly lower values than that of the control treatment (Table 2). At $28 \mathrm{dpi}$, ELISA values were significantly lower for plants treated with biopreparation G/INR7 than for G/T4 and the control treatment, but no other differences were observed (Table 2).

When the disease severity rating was considered only among plants infected at $14 \mathrm{dpi}$ (Table 2), all treatments continued to have a significantly lower rating than the control (Fig. 3B). In addition, tomato plants treated with G/IN937a had ratings signifi-
No CMV

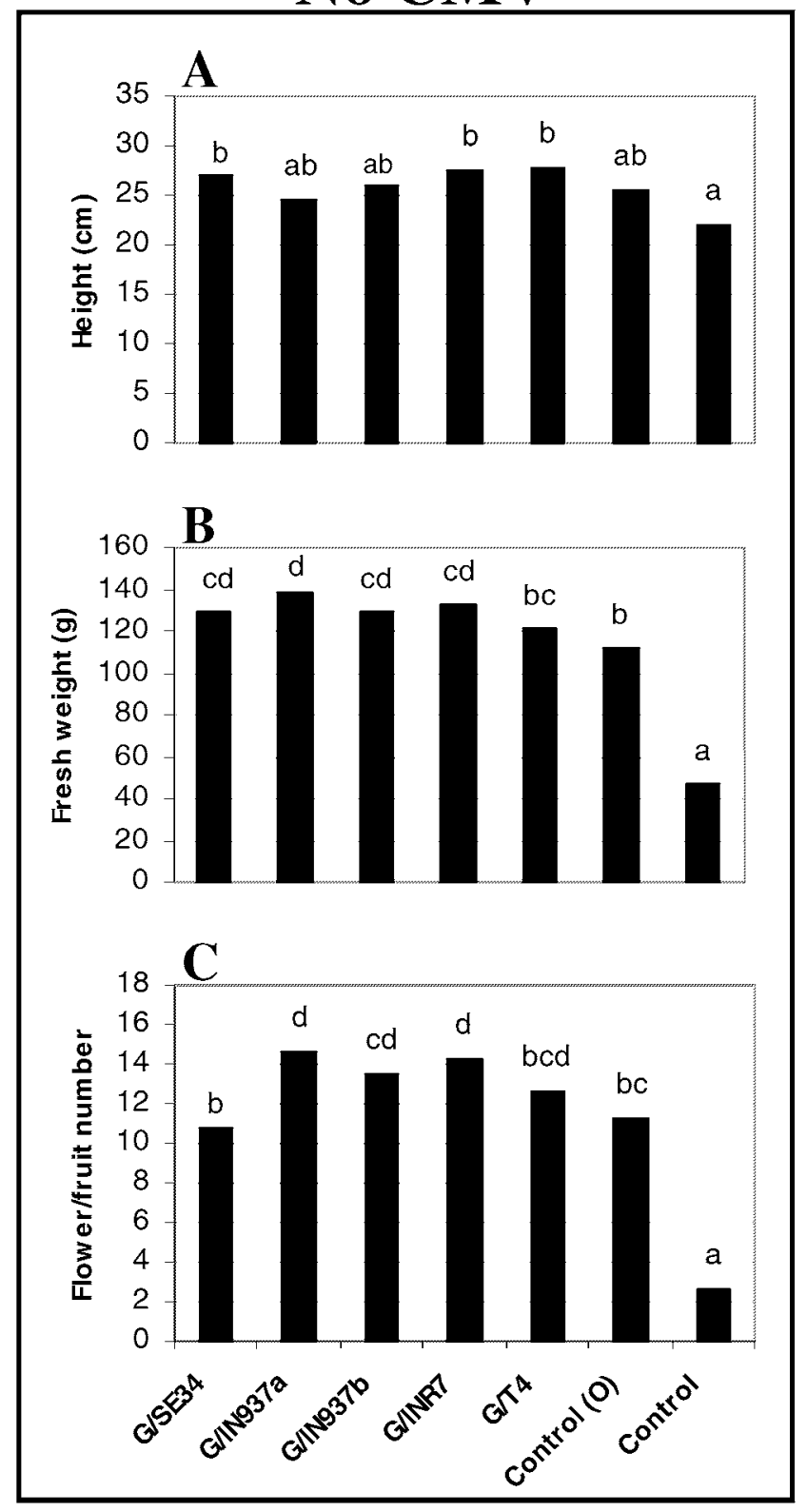

CMV
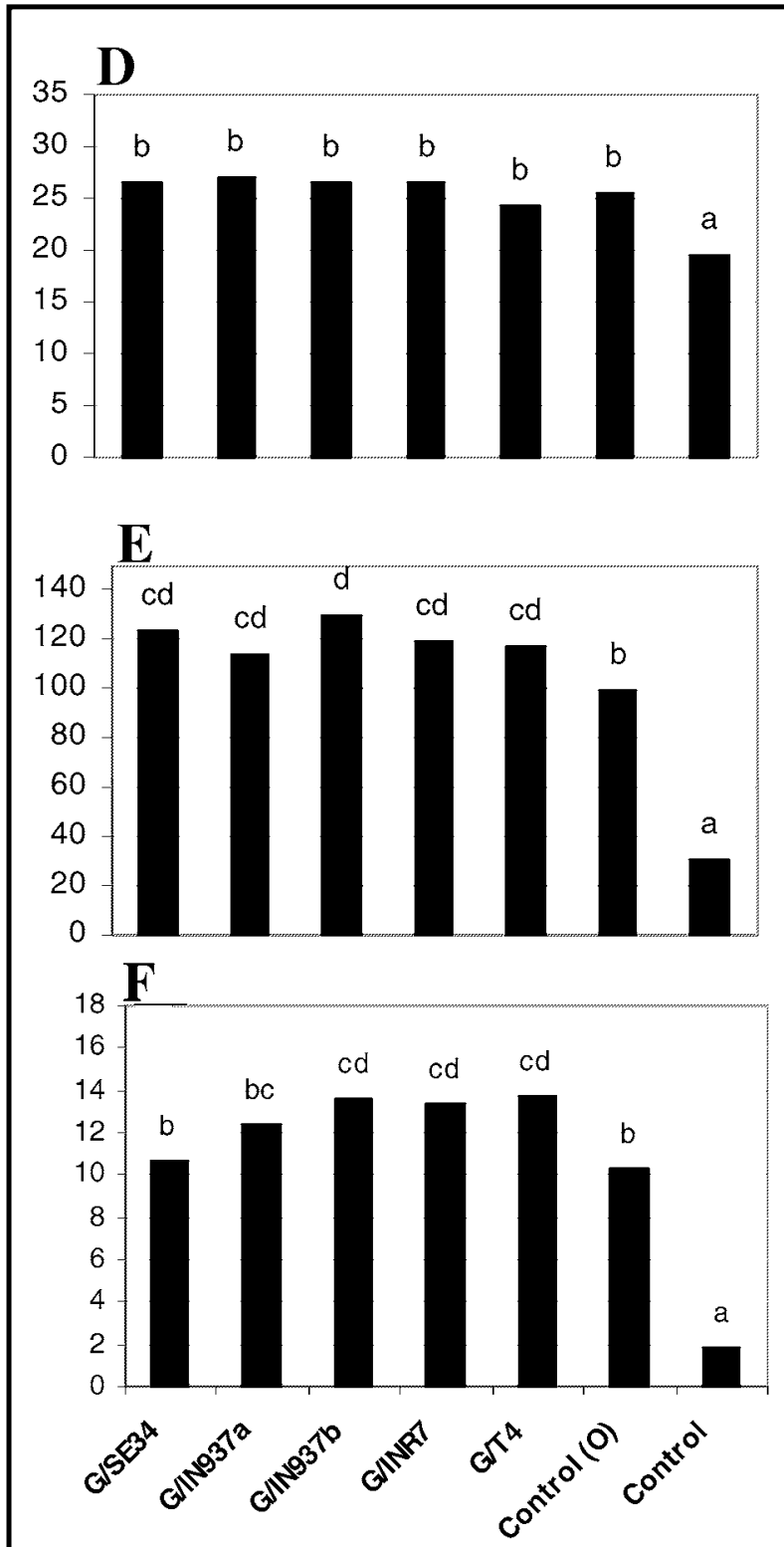

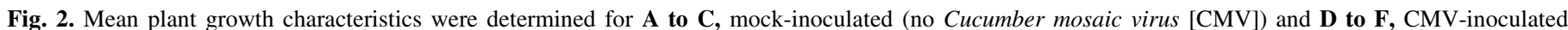

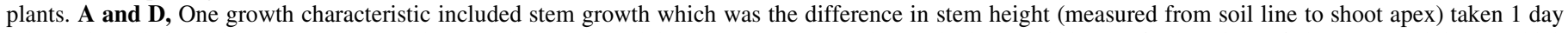

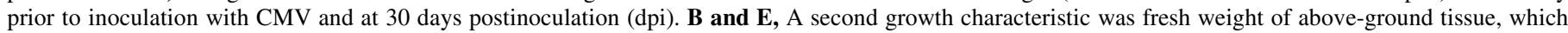

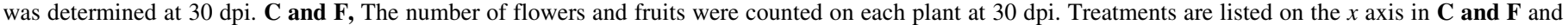

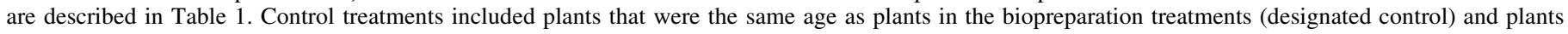

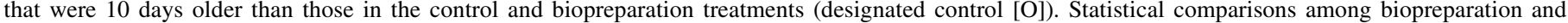

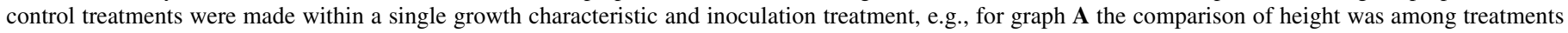

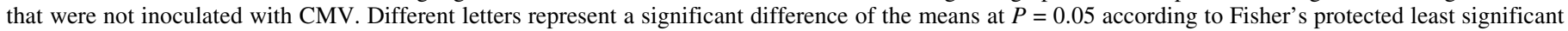
difference test. 
cantly lower than that of plants treated with biopreparation G/IN937b and the older control. At $28 \mathrm{dpi}$, only treatments G/IN937a, G/IN937b, and G/T4 and the older control were less severely affected than plants in the control treatment (Fig. 3B). Furthermore, biopreparation G/IN937b resulted in a disease severity rating significantly lower than that of plants treated with G/SE34 and G/INR7.

\section{DISCUSSION}

The biopreparations used in this study significantly enhanced growth of tomato plants relative to plants of the same age nonbacterized control treatment. We hypothesized that the enhanced rate of plant growth achieved with the biopreparations would reduce the time during which infection of plants would lead to the development of severe CMV-induced symptoms. The biopreparation-treated plants would therefore respond to CMV infection in a manner similar to that of more mature plants despite their young age. Indeed, plants in each of the biopreparation treatments responded to CMV in a manner similar to that of plants that were 10 days older (i.e., the older control). Generally, mean disease ratings, percentage of infected plants, and virus accumulation levels were similar among biopreparation-treated plants and plants that were 10 days older, but these were significantly lower than observed for plants in the control treatment that were the same age but smaller at the time of inoculation. Furthermore, among plants that were infected, the mean level of CMV accumulation for those treated with biopreparations G/IN937a, G/IN937b, and G/T4 and the older control was significantly less than for those of the control treatment at $14 \mathrm{dpi}$. The differences between the larger plants (i.e., those treated with biopreparations and the older control) and the smaller plants (i.e., same age control) were more pronounced at $14 \mathrm{dpi}$ than at $28 \mathrm{dpi}$. Interestingly, many of the plants in the biopreparation and older control treatments were systemically infected with CMV at $14 \mathrm{dpi}$, as shown by ELISA; however, they did not express symptoms. In a few cases, when symptoms did appear in these plants by $28 \mathrm{dpi}$, they were relatively severe. Furthermore, the appearance of symptoms later in the experiment in biopreparation-treated and older control plants had little effect on overall plant growth and development because few differences occurred between CMV- and mock-inoculated treatments (i.e., comparison of growth parameters in Figure $2 \mathrm{~A}$ to $\mathrm{C}$ with the respective growth parameter in $\mathrm{D}$ to $\mathrm{F}$ ). An important point here is that the growth and development and response to CMV inoculation for plants in the biopreparation treatments paralleled that of plants in the older control treatment and differed (in most cases significantly) from that of plants in the same age control treatment.

We showed that various PGPR strains were able to induce resistance in cucumber and tomato against CMV $(24,36)$ and ToMoV

TABLE 2. Enzyme-linked immunosorbent assay (ELISA) values and percent infection of tomato plants treated with different biopreparations and challenged with Cucumber mosaic virus (CMV)

\begin{tabular}{|c|c|c|c|c|}
\hline \multirow[b]{2}{*}{ Treatment $^{\mathrm{x}}$} & \multicolumn{2}{|c|}{ ELISA $^{y}$} & \multicolumn{2}{|c|}{ Percent infection $^{\mathrm{z}}$} \\
\hline & $14 \mathrm{dpi}$ & $28 \mathrm{dpi}$ & 14 dpi & $28 \mathrm{dpi}$ \\
\hline \multirow[t]{2}{*}{ G/SE34 } & $0.440 \mathrm{~cd}$ & $0.296 \mathrm{~b}$ & $35.0 \mathrm{~cd}$ & $27.5 \mathrm{c}$ \\
\hline & $1.028 \mathrm{ab}$ & $0.779 \mathrm{ab}$ & & \\
\hline \multirow{2}{*}{ G/IN937a } & $0.292 \mathrm{~d}$ & $0.333 \mathrm{~b}$ & $22.5 \mathrm{~d}$ & $35.0 \mathrm{bc}$ \\
\hline & $0.857 \mathrm{~b}$ & $0.706 \mathrm{ab}$ & & \\
\hline \multirow[t]{2}{*}{ G/IN937b } & $0.363 \mathrm{~d}$ & $0.391 \mathrm{~b}$ & $37.5 \mathrm{~cd}$ & $47.5 \mathrm{~b}$ \\
\hline & $0.752 \mathrm{~b}$ & $0.716 \mathrm{ab}$ & & \\
\hline \multirow[t]{2}{*}{ G/INR7 } & $0.590 \mathrm{bc}$ & $0.398 \mathrm{~b}$ & $55.0 \mathrm{bc}$ & $52.5 \mathrm{~b}$ \\
\hline & $0.995 \mathrm{ab}$ & $0.644 \mathrm{~b}$ & & \\
\hline \multirow[t]{2}{*}{ G/T4 } & $0.719 \mathrm{~b}$ & $0.722 \mathrm{a}$ & $72.5 \mathrm{ab}$ & $85.0 \mathrm{a}$ \\
\hline & $0.941 \mathrm{~b}$ & $0.847 \mathrm{a}$ & & \\
\hline \multirow[t]{2}{*}{ Control (old) } & $0.410 \mathrm{~cd}$ & $0.380 \mathrm{~b}$ & $32.5 \mathrm{~cd}$ & $40.0 \mathrm{bc}$ \\
\hline & $0.931 \mathrm{~b}$ & $0.685 \mathrm{ab}$ & & \\
\hline \multirow[t]{2}{*}{ Control } & $1.228 \mathrm{a}$ & $0.822 \mathrm{a}$ & $87.5 \mathrm{a}$ & $87.5 \mathrm{a}$ \\
\hline & $1.252 \mathrm{a}$ & $0.900 \mathrm{a}$ & & \\
\hline
\end{tabular}

${ }^{x}$ Each biopreparation treatment consisted of endospore preparations of two plant growth-promoting rhizobacteria strains formulated with the carrier chitosan (Table 1). Nonbacterized control treatments included plants that were 10 days older than those in the biopreparations (designated control [old]) and plants that were the same age as those in the biopreparations (control).

y Mean ELISA values for CMV-inoculated tomato plants subjected to the stated treatments. Numbers in the upper row represent the mean ELISA value for all (40) plants per treatment, whereas the lower row of numbers represents the mean ELISA value only for the infected plants. Samples were considered positive for the presence of CMV when the absorbance value was greater than the mean plus 3 standard deviations for comparable healthy control samples. Different letters represent a significant difference of the means within like treatments and sampling dates at $P=0.05$ according to Fisher's protected least significant difference (LSD) test.

${ }^{\mathrm{z}}$ Percent infection is based on the number of samples infected with CMV based on ELISA per 40 samples for each treatment. Different letters represent a significant difference of the means within like treatments and sampling dates at $P=0.05$ according to Fisher's protected LSD test.

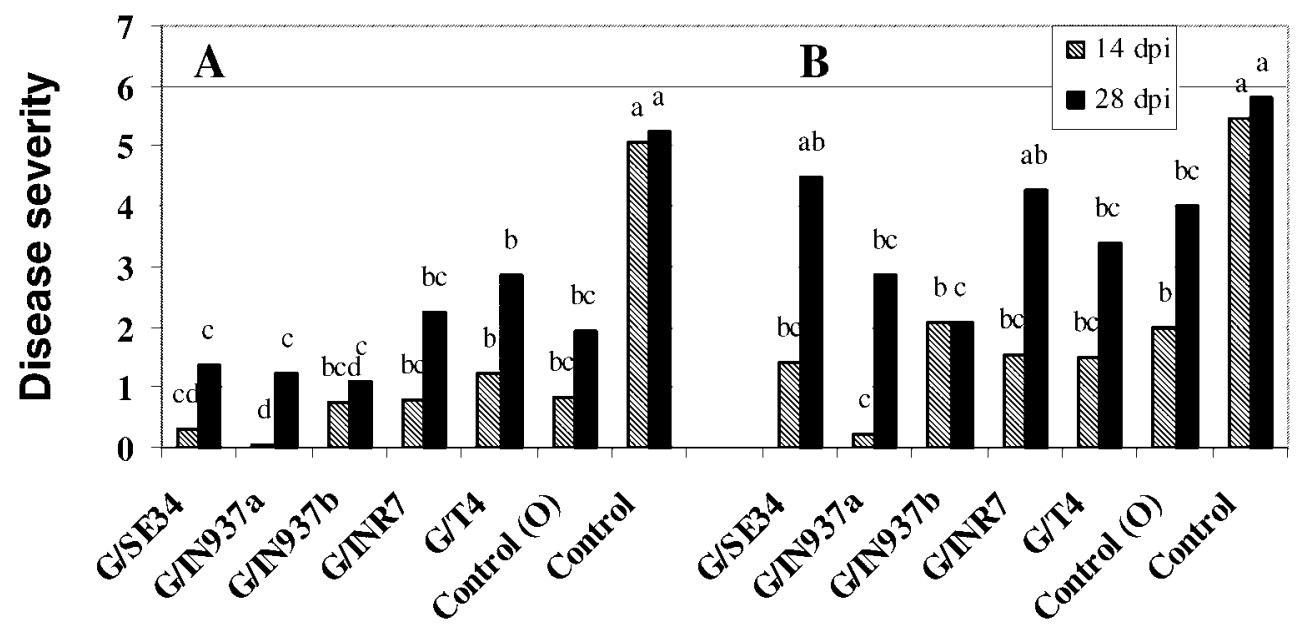

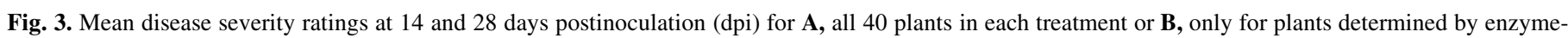

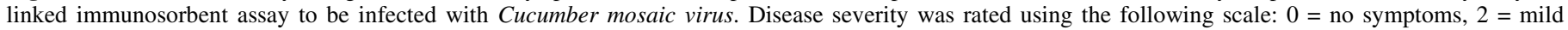

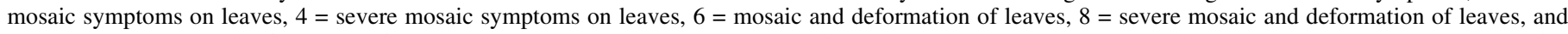

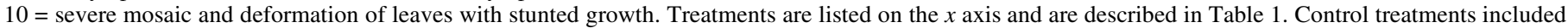

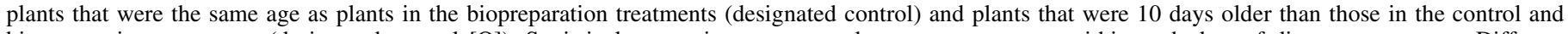

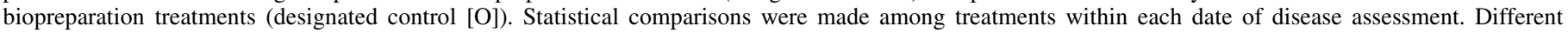
letters represent a significant difference of the means at $P=0.05$ according to Fisher's protected least significant difference test. 
(18). PGPR-treated cucumber plants that were symptomless contained no detectable amounts of CMV in young, noninoculated leaves, whereas those that developed symptoms behaved similar to those of CMV-infected plants in the nonbacterized control treatment (24). PGPR-treated tomato plants were less severely affected by CMV than control plants, but data were not collected to determine levels of CMV accumulation in foliar tissues (24). Zehnder et al. (36) also identified PGPR strains that provided protection against CMV in the form of reduced disease severity ratings under greenhouse conditions. In the studies evaluating the response of PGPR-treated cucumber and tomato to inoculation with CMV in the greenhouse and ToMoV (18) in tomato carried out in the field, PGPR treatments induced protection against virus in the form of no symptoms, reduced symptoms, and in some cases, no detectable accumulation of virus. In this current report, we describe similar responses in tomato to inoculation by CMV; however, the inducing agent differs from previous work and the host response to this treatment is a distinctly different phenomenon. The inducing agent used in this study consisted of combinations of two PGPR strains, shown previously to induce resistance to various plant pathogens, and the carrier chitosan. These biopreparations were industrially formulated and developed for broad-spectrum protection under varying environmental conditions (12). Treatment of tomato plants with these biopreparations resulted in rapid and enhanced plant growth, and as shown in Figure 2, this growth was significantly greater than that of nontreated plants (control treatment). The biopreparation-treated plants were phenotypically, and perhaps developmentally, similar to plants that were 10 days older. It should be noted that inoculation of biopreparation-treated tomato plants with CMV shortly after germination, e.g., biopreparation-treated plants were at the three- to five-leaf stage, resulted in $100 \%$ infection; however, the enhanced plant growth subsequent to inoculation resulted in milder symptoms and a greater degree of recovery than normally observed (data not shown). Since in the previous studies enhanced plant growth did not occur in response to treatment with PGPR, the resistance to CMV likely resulted from induced resistance $(18,24,36)$. In the current study, the protection afforded biopreparation-treated plants appears to have resulted from the enhanced growth of tomato plants, thereby allowing them to respond to inoculation with CMV similar to that of more mature plants. Indeed, disease severity ratings at $14 \mathrm{dpi}$ for plants infected were significantly milder in each biopreparation treatment and the older control relative to plants in the control treatment. These lower disease ratings also occurred at $28 \mathrm{dpi}$ for all but two of the biopreparation treatments. Although infected PGPR and older control plants tended to have milder symptoms than observed in the infected control, levels of virus accumulation in noninoculated leaves did not always correlate with symptom severity. For example, although tomato plants treated with G/IN937a, G/IN937b, and G/T4 and the older control did not differ from plants in the control treatment for CMV accumulation levels at $28 \mathrm{dpi}$, they had significantly milder symptoms compared with the control. Also, biopreparation G/INR7-treated plants contained significantly less virus at 28 dpi relative to the control treatment, but no difference in disease severity. These observations and those of overall means suggest that a significant number of biopreparation-treated plants (and those in the older control) resist systemic infection (we did not evaluate local infection), but once infected, factors other than virus levels at specific dates postinoculation control symptom severity.

Consideration of the viral infection process might lead one to speculate that conditions that enhance plant growth may in turn create an environment that enhances virus accumulation and translocation throughout the plant. This scenario was observed with regard to plant nutrition where conditions that favored plant growth also favored virus accumulation $(3,6,19)$. In contrast to enhanced plant growth and virus accumulation by nutritional factors, the biopreparations enhanced plant growth without any associated enhancement of CMV accumulation. Virus infection typically has a negative effect on photosynthesis and allocation of resources between organs, which leads to the characteristic chlorosis and mosaic symptoms (11), therefore, nutritional factors, especially nitrogen levels, could serve to offset or mask these abnormalities in cellular physiology. This masking of symptoms may have played a role during the early stages of systemic infection of biopreparation-treated plants by CMV when symptoms were not apparent, even though virus accumulation was similar to that of control treatment plants.

Our findings raise two intriguing questions: (i) what defines a mature plant, and (ii) what defines mature plant resistance? We showed that bell pepper plants grown under greenhouse conditions were able to express, what we considered to be, mature plant resistance to infection by CMV (10). This resistance in more mature bell pepper plants was expressed as a lack of CMV symptoms with little or no virus detected in the stem and in young, noninoculated leaves. Interestingly, CMV accumulated to higher levels in inoculated leaves of older plants than young plants. Thus, in the mature bell pepper plants, it appeared that the resistance against CMV was interference in processes associated with systemic infection (10). CMV infection of mature bell pepper plants has similarities with CMV infection of biopreparation-treated tomato plants. However, in the case of the biopreparation-treated tomato plants, these plants were actually young in age, but phenotypically and perhaps developmentally more mature.

Because mature plant resistance has been used as a management tool to reduce virus infection and associated yield losses under field conditions $(1,2,5,8,13,15,16,21,26-28,31,32)$, use of the biopreparation formulations reported here may provide a rapid onset of plant maturity that will integrate well with other pest management schemes.

\section{ACKNOWLEDGMENTS}

This research was supported by U.S. Department of Agriculture National Research Initiative Award 99-34103-8066. We thank M. Eubanks for assistance with statistical analyses.

\section{LITERATURE CITED}

1. Agrios, G. N., Walker, M. E., and Ferro, D. N. 1985. Effects of Cucumber mosaic virus inoculation at successive weekly intervals on growth and yield of pepper (Capsicum annuum) plants. Plant Dis. 69:5255 .

2. Avilla, C., Collar, J. L., Duque, M., and Fereres, A. 1997. Yield of bell pepper (Capsicum annuum) inoculated with CMV and/or PVY at different time intervals. Z. Ptlanzenkr. Ptlanzenschtz 104:1-8.

3. Bawden, F. C., and Kassanis, B. 1950. Some effects on host nutrition on the susceptibility of plants to infection by certain viruses. Ann. Appl. Biol. 37:46-57.

4. Benhamou, N., Kloepper, J. W., and Tuzun, S. 1998. Induction of resistance against Fusarium wilt of tomato by combination of chitosan with an endophytic bacterial strain: Ultrastructure and cytochemistry of the host response. Planta 204:153-168.

5. Bosque-Perez, N. A., Olojede, S. O., and Buddenhagen, I. W. 1998. Effect of maize streak virus disease on the growth and yield of maize as influenced by varietal resistance levels and plant stage at time of challenge. Euphytica 101:307-317.

6. Cheo, P., Pound, G. S., and Weathers, L. G. 1952. The relation of host nutrition to the concentration of cucumber mosaic virus in spinach. Phytopathology 42:377-381.

7. De Meyer, G., Audenaert, K., and Hofte, M. 1999. Pseudomonas aeruginosa 7NSK2-induced systemic resistance in tobacco depends on in planta salicylic acid but is not associated with PR1a expression. Eur. J. Plant Pathol. 105:513-517.

8. Demski, J. W., and Chalkley, J. H. 1974. Influence of watermelon mosaic virus on watermelon. Plant Dis. 58:195-198.

9. DiFonzo, C. D., Ragsdale, D. W., Radcliffe, E. B., and Banttari, E. E. 1994. Susceptibility to potato leafroll virus in potato: Effects of cultivar, plant age at inoculation, and inoculation pressure on tuber infection. Plant Dis. 78:1173-1177. 
10. Garcia-Ruiz, H., and Murphy, J. F. 2001. Age-related resistance in bell pepper to Cucumber mosaic virus. Ann. Appl. Biol. 139:307-317.

11. Hull, R. 2002. Transmission 2: Mechanical, seed, pollen and epidemiology. Pages 540-541 in: Matthews' Plant Virology. Academic Press, New York.

12. Kloepper, J. W., Reddy, M. S., Kenney, D. S., Kokalis-Burelle, N., Martinez-Ochoa, N., and Vavrina, C. S. Theory and applications of rhizobacteria for transplant production and yield enhancement. Acta Hortic. (In Press.)

13. Knutson, K. W., and Bishop, G. W. 1964. Potato leafroll virus- effect of date of inoculation on percent infection and symptom expression. Am. Potato J. 41:227-238.

14. Leisner, S. M., and Turgeon, R. 1993. Movement of virus and photoassimilate in the phloem: A comparative analysis. BioEssays 15:741748.

15. Loebenstein, G. 1972. Localization and induced resistance in virusinfected plants. Annu. Rev. Phytopathol. 10:177-206.

16. Lot, H., Chovelon, V., Souche, S., and Delecolle, B. 1998. Effects of onion yellow dwarf and leek yellow stripe viruses on symptomatology and yield loss of three French garlic cultivars. Plant Dis. 82:13811385.

17. Maurhofer, M., Hase, C., Meuwly, P., Metraux, J.-P., and Defago, G. 1994. Induction of systemic resistance of tobacco to tobacco necrosis virus by the root-colonizing Pseudomonas fluorescens strain CHA0: Influence of the gacA gene and of pyoverdine production. Phytopathology 84:139-146.

18. Murphy, J. F., Zehnder, G. W., Schuster, D. J., Sikora, E. J., Polston, J. E., and Kloepper, J. W. 2000. Plant growth-promoting rhizobacterial mediated protection in tomato against Tomato mottle virus. Plant Dis. 84:779-784.

19. Navas, M. L., Friess, N., and Maillet, J. 1998. Influence of cucumber mosaic virus infection on the growth response of Portulaca oleracea (purslane) and Stellaria media (chickweed) to nitrogen availability. New Phytol. 139:301-309.

20. Palukaitis, P., Roossinck, M. J., Dietzgen, R. G., and Francki, R. I. B. 1992. Cucumber mosaic virus. Adv. Virus Res. 41:281-348.

21. Pasko, P. J., Nicklow, C. W., and Moorman, G. W. 1984. Factors influencing cucumber mosaic virus symptom development in pepper. HortScience 19:586-587.

22. Populer, C. 1978. Changes in host susceptibility with time. Pages 239262 in: Plant Disease, and Advanced Treatise. Vol. II. J. G. Horsfall and E. B. Cowling, eds. Academic Press, New York.
23. Raupach, G. S., and Kloepper, J. W. 2000. Biocontrol of cucumber diseases in the field by plant growth-promoting rhizobacteria with and without methyl bromide fumigation. Plant Dis. 84:1073-1075.

24. Raupach, G. S., Liu, L., Murphy, J. F., Tuzun, S., and Kloepper, J. W. 1996. Induced systemic resistance against cucumber mosaic cucumovirus using plant growth-promoting rhizobacteria (PGPR). Plant Dis. 80:891-894.

25. Rodriquez-Kabana, R., Morgan-Jones, G., and Chet, I. 1987. Biological control of nematodes: Soil amendments and microbial antagonists. Plant Soil 100:237-247.

26. Rosenkranz, E., and Scott, G. E. 1978. Effect of plant age at the time of inoculation with maize dwarf mosaic virus on disease development and yield in corn. Phytopathology 68:1688-1692.

27. Ross, J. P. 1969. Effect of time and sequence of inoculation of soybeans with soybean mosaic and bean pod mottle viruses on yields and seed characters. Phytopathology 59:1404-1408.

28. Scott, G. E., Rosenkranz, E. E., and Nelson, L. R. 1977. Yield loss of corn due to corn stunt disease complex. Agron. J. 69:92-94.

29. Sikora, E. J., Gudauskas, R. T., Murphy, J. F., Porch, D. W., Andrianifahanana, M., Zehnder, G. W., Bauske, E. M., Kemble, J. M., and Lester, D. 1998. A multivirus epidemic of tomatoes in Alabama. Plant Dis. 82:117-120.

30. Smith, G., and Parlevliet, J. E. 1990. Mature plant resistance of barley to barley leaf rust, another type of resistance. Euphytica 50:159-162.

31. Soler, S., Díez, M. J., and Nuez, F. 1998. Effect of temperature regime and growth stage interaction on pattern of virus presence in TSWVresistant accessions of Capsicum chinense. Plant Dis. 82:1199-1204.

32. Thongmeearkom, P., Pascal, E. H., II, and Goodman, R. M. 1978. Yield reductions in soybeans infected with cowpea mosaic virus. Phytopathology 68:1549-1551.

33. Ton, J., Van Pelt, J. A., Van Loon, L. C., and Pieterse, C. M. J. 2002. The Arabidopsis ISRI locus is required for rhizobacteria-mediated induced systemic resistance against different pathogens. Plant Biol. 4:224-227.

34. Ton, J., Van Pelt, J. A., Van Loon, L. C., and Pieterse, C. M. J. 2002. Differential effectiveness of salicylate-dependent and jasmonate/ethylenedependent induced resistance in Arabidopsis. Mol. Plant-Microbe Interact. 15:27-34.

35. Walkey, D. 1991. Applied Plant Virology, 2nd ed. Chapman and Hall, New York.

36. Zehnder, G. W., Yao, C., Murphy, J. F., Sikora, E. J., and Kloepper, J. W. 2000. Induction of resistance in tomato against cucumber mosaic cucumovirus by plant growth-promoting rhizobacteria. BioControl 45:127-137. 